(C) 2022, The Authors. Published by Elsevier Inc. and Fass Inc. on behalf of the American Dairy Science Association ${ }^{\circledR}$. This is an open access article under the CC BY license (http://creativecommons.org/licenses/by/4.0/).

\title{
M-score and wound healing assessment of 2 nonantibiotic topical gel treatments of active digital dermatitis lesions in dairy cattle
}

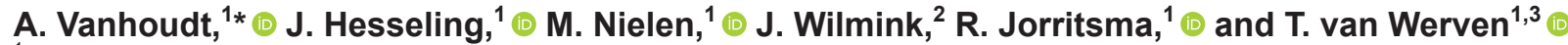 \\ ${ }^{1}$ Department of Population Health Sciences, Faculty of Veterinary Medicine, Utrecht University, $3584 \mathrm{CL}$, Utrecht, the Netherlands \\ ${ }^{2}$ Woumarec, 6705 CT, Wageningen, the Netherlands \\ ${ }^{3}$ University Farm Animal Practice, 3481 LZ, Harmelen, the Netherlands
}

\begin{abstract}
This open-label, randomized clinical trial with positive control compared the treatment of active digital dermatitis (DD) lesions (stages M1, M2, and M4.1) on dairy cattle hind feet with an enzyme alginogel or a copper and zinc chelate gel (coppergel). Upon recruitment (d 0), active DD lesions were cleaned, photographed, treated, and bandaged. This procedure was repeated on $\mathrm{d} 3$ and $\mathrm{d} 7$, with treatment and bandaging discontinued for those lesions that had transitioned to the M0, M3, or M4 stage on d 7. Day 10 was considered the end of the treatment trial, and all recruited feet were cleaned and photographed. Treatment effect of the 2 products was assessed not only using the M-score but also using general wound healing progress criteria. Improvement of M-score was defined as transition to M0, M3, or M4 stages, or to lesions with a smaller ulcerative area (e.g., M2 stage to M1 stage). Lesions with improved wound healing had at least one of the following criteria when compared with the previous observation: decreased defect size, healthier granulation tissue color (pinkred instead of purple-grayish), more regular aspect of granulation tissue surface, wound contraction, or epithelization starting from the surrounding skin. Both primary outcomes were assessed using a multivariable logistic regression analysis. Lesions treated with the enzyme alginogel had a decreased adjusted odds ratio for M-score improvement (aOR: 0.04; 95\% confidence interval: 0.01-0.11). Lesions treated with the coppergel mostly transitioned to chronic lesions, whereas lesions treated with the enzyme alginogel mostly remained active lesions. The wound healing progress of almost $70 \%$ of the lesions treated with coppergel could not be scored, for the greater part due to the presence of crust materials. With these unscorable lesions classified as "improved," there was no treatment effect on wound healing progress (aOR: 0.99; 95\% confidence interval:
\end{abstract}

Received April 15, 2021.

Accepted August 23, 2021.

*Corresponding author: a.vanhoudt@uu.nl
0.34-3.05), whereas with unscorable lesions classified as "not improved," the enzyme alginogel outperformed the coppergel with regard to wound healing progress (aOR: 2.48; $95 \%$ confidence interval: $1.07-5.79$ ). None of the products used in our study achieved high cure rates (transition to the M0 stage) for active DD lesions. Low cure rates of topical treatment of DD, together with the important role of chronic lesions in the epidemiology of $\mathrm{DD}$, indicate that future research should investigate how to achieve successful wound management of DD lesions, thereby mitigating pain associated with the lesions and reducing both transmission and prevalence of DD within herds.

Key words: digital dermatitis, randomized clinical trial, nonantibiotic, enzyme alginogel, wound management

\section{INTRODUCTION}

Digital dermatitis (DD) is considered a contagious disease and an important cause of lameness in dairy cattle worldwide. It is characterized by hyperkeratotic or ulcerative lesions, typically located on the plantar or palmar aspect of the foot, immediately proximal to the interdigital cleft. Lesions are mostly present on the hind feet and are associated with lameness, reduced milk production, diminished reproductive performance, and decreased animal welfare (Bruijnis et al., 2012; Higginson Cutler et al., 2013; Dolecheck and Bewley, 2018).

Ulcerative lesions are commonly grouped as active lesions and consist of the M1, M2, and M4.1 stage lesions, whereas M3 and M4 stage lesions are considered chronic lesions (Zinicola et al., 2015; Biemans et al., 2018). In general, alongside herd-level DD control through foot bathing, cows with active DD lesions receive a topical treatment with or without bandage (Plummer and Krull, 2017). Topical treatments contain either antibiotics (e.g., broad-spectrum tetracyclines) or a nonantibiotic active compound (e.g., copper and zinc chelates). Products based on copper and zinc chelates are widely used in the Netherlands and are reported as an effective treatment option for DD com- 
pared with topical tetracyclines, with cure rates of 85 to $90 \%$ versus 45 to $55 \%$, respectively (Holzhauer et al., 2011; Dotinga et al., 2017). These cure rates do not necessarily imply return to normal, unaffected skin, but mostly resemble progress of the lesion to a chronic, nonulcerative, hyperkeratotic M-stage. With this approach, the disease is kept in a manageable state (Döpfer and Bonino Morlán, 2008).

The lesions of DD can also be considered chronic, nonhealing wounds with a bacterial infection. Secondintention wound healing is a complex interaction between several cell types, the extracellular matrix and mediators that coordinate the process. This process can arbitrarily be differentiated into 4 phases: hemostasis, acute inflammation, proliferation, and remodeling (Theoret, 2017). Wound healing evaluation often involves repeated assessments of the size of the lesion (occurrence of wound contraction and epithelization) and presence of clinical signs that can promote or indicate local infection, such as tissue necrosis, unhealthy granulation tissue (friable, purple or grayish color, irregular aspect), exudation, pocketing, undermining of skin, or sometimes only delayed healing (Lazarus et al., 1994; Theoret, 2017). Management of chronic, open wounds is based on the TIME principle (tissue debridement, infection control, moisture balance, and edges of the wound) and aims at return to normal unaffected skin or a functional epithelial scar (Schultz et al., 2003; Leaper et al., 2012; Bowers and Franco, 2020). Since its first introduction, novel products and strategies have emerged to aid in achieving the TIME principle, with enzymatic alginates being one of them. Recently, an enzyme alginogel has appeared effective in the treatment of udder cleft dermatitis, an ulcerative dermatitis, in dairy cows (van Werven et al., 2018). Alginates are known for their capacity to absorb debris and exudate (passive debridement) and for keeping wounds moist through their gelling capacity (moisture balance; Strohal et al., 2013; Jacobsen, 2017; Jones and Oates, 2018). The alginates in the alginogel absorb bacteria into the gel matrix. In this matrix, the antimicrobial enzyme system of glucose oxidase, lactoperoxidase, and guaiacol (GLG-enzyme system) effects a controlled release of reactive oxygen species, which selectively disrupt bacterial cell walls (infection control; De Smet et al., 2009).

We hypothesized that an enzyme alginogel is an effective topical treatment for wound healing of active DD lesions. To test this hypothesis, we compared the enzyme alginogel with the standard nonantibiotic topical treatment used in the Netherlands, a copper and zinc chelates gel. Effectiveness of treatment was evaluated using both the M-score for DD (Döpfer et al., 1997; Berry et al., 2012) and wound healing criteria (Theoret, 2017).

\section{MATERIALS AND METHODS}

\section{Ethical Statement}

This study was performed in conformation with European law concerning the protection of animals kept for farming purposes (Council Directive 98/58/EC) and was not considered an animal experiment under Dutch legislation. Farmers participated in the research based on an informed consent statement.

\section{Study Design}

This open-label, randomized clinical trial with positive control was set up as an intention-to-treat, noninferiority trial to compare the treatment of active DD lesions with an enzyme alginogel [treatment group (alginogel), BoTop, Flen Health; none of the components require a maximum residue level, and therefore there is no authorization number nor withdrawal period] or with a copper and zinc chelates gel [control group (coppergel), Intra Hoof-fit Gel, Intracare; authorization number RegNL 109438, 0-d withdrawal period for both milk and meat]. For welfare reasons, an untreated negative control group was not included in the study design. Randomization was blocked by farm with pseudorandomization at cow level by flipping a coin for the first cow with an active DD lesion on each farm. Sample size was calculated a priori using the Farrington-Manning score test for proportion difference in SAS (version 9.4M5, SAS Institute Inc.), with a difference greater than $10 \%$ indicating inferiority. The expected M-score improvement rate of the coppergel was set at $92 \%$ (Holzhauer et al., 2011). Considering a 95\% confidence interval (CI) and a power of $80 \%$ resulted in a calculated sample size of at least 104 active DD lesions in each group.

\section{Scorer Training}

Four students in veterinary medicine were trained in applying the M-score (Döpfer et al., 1997; Berry et al., 2012) by studying the literature, classroom training (39 digital color photographs of cattle feet with varying Mstages, $61 \%$ agreement between the 4 scorers), and 1 inparlor M-scoring of washed hind feet of approximately 50 dairy cows together with the first author (Relun et al., 2011; Solano et al., 2017).

\section{Herd Selection}

Veterinarians working in the Utrecht area were contacted and asked to suggest dairy farms that would meet the selection criteria for the study: (1) herds esti- 
mated to have a high $(>20 \%)$ prevalence of cows with active DD lesions, (2) presence of a safe and functional trimming chute on the farm, (3) lactating herd size of at least 50 cows, and (4) willingness to participate in the study. This resulted in a convenience sample of 7 farms. Farms were recruited between January 20 and February 20, 2019.

\section{Treatment Protocol}

At each M-score assessment of the feet, a spreading plier was available to allow inspection of the interdigital cleft. All treatments were applied by trained veterinary students. Upon recruitment (d 0), on all farms but one, the hind feet of all lactating cows were given a foot trim according to the Dutch 5-step method (Toussaint Raven, 1989) by the herd's regular hoof trimmer, and all feet of these cows were given an M-score by a trained veterinary student. On one farm (farm 1), the farmer selected 43 cows (out of 118 lactating cows) for foot trimming, because they were lame, likely to have an active DD lesion, or both. Hind feet with an active DD lesion (i.e., lesions of stage M1, M2, or M4.1; Zinicola et al., 2015; Biemans et al., 2018), were selected for topical treatment. The first case on a farm was allocated to the alginogel or coppergel group by flipping a coin. Thereafter, cows were alternately allocated to the alginogel or coppergel group. All active DD lesions within one cow received the same treatment, to exclude a potential systemic effect of the treatment product. Before applying a treatment, lesions were cleaned with cold water, a paper towel, or both, and a photograph was taken (Sony Cybershot DSC-W830, Sony). The treatment product was applied directly to the lesion so that it covered the entire lesion, and then the treated lesion was covered with a nonaqueous, non-linting gauze dressing that was impregnated with a water-repellent ointment (Cuticerin gauze dressing, $10 \times 10 \mathrm{~cm}$, Smith and Nephew). The foot was then bandaged with soft padding (Cellona, Lohmann and Rauscher), vetwrap (EickWrap, Eickenmeyer), and tape (Leukoplast, BSN Medical; Figure 1). On d 3, the bandage was removed in a trimming chute, and the foot was gently rinsed with cold water and dried with a paper towel. The lesion was then given an M-score, photographed, and, irrespective of the M-score on d 3, treated under bandage with the same product that was used on $\mathrm{d} 0$, as described previously. On d 7 this procedure was repeated for feet with active lesions. Feet without active DD lesions on $d 7$ were only M-scored and photographed, and received no further treatment nor bandage. All feet recruited on d 0 were given a final M-score and photographed on d 10 after rinsing with cold water and drying with a paper towel. Day 10 was considered the endpoint of the treatment period. For welfare reasons, lesions that were still active at d 10 were treated according to the farm treatment protocol, which was mostly a tetracycline spray or the coppergel without bandage. Due to logistical reasons, the $\mathrm{d} 10$ evaluation took place on $\mathrm{d}$ 9 on farm 5 . The students were aware of the treatment allocation in such a way that they applied and recorded the initial treatment on $\mathrm{d} 0$ and could see the different color of the treatment products (green for coppergel and transparent for alginogel) when replacing the bandage. The students would always first M-score the lesion and then check the treatment allocation of the lesion for further treatment according to the protocol. The treatment allocation of the lesions was masked for the farmers. Farmers were not allowed to run the cows through a footbath during the 10-d trial period.

\section{Treatment Outcomes}

M-Score. Improvement of M-score, including cure, between d 0 and d 10 (MS0-10; Table 1) was the primary outcome and was investigated using an M-score
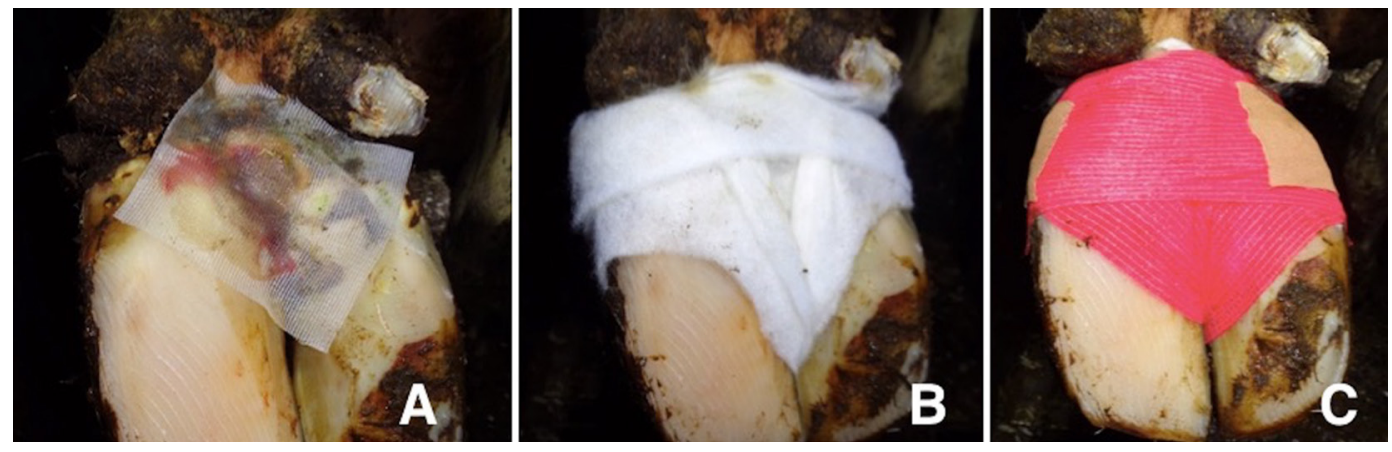

Figure 1. The digital dermatitis lesion was fully covered with the treatment product (in this photograph, enzyme alginogel) and covered with an impregnated, non-aqueous, non-linting gauze dressing (A). The foot was then bandaged with a soft padding (B) and with vetwrap and tape (C). 
Table 1. Definitions of improvement and cure following nonantibiotic topical treatment with bandage of active digital dermatitis lesions using M-scores (Döpfer et al., 1997; Berry et al., 2012) at the start (d $0)$ and end (d 10) of the treatment trial

\begin{tabular}{lll}
\hline & \multicolumn{2}{c}{ M-score on d 10 } \\
\cline { 2 - 3 } M-score & Improvement & Cure \\
\hline M1 & M0, M3, and M4 & M0 \\
M2 & M0, M1, M3, M4, and M4.1 & M0 \\
M4.1 & M0, M1, M3, and M4 & M0 \\
\hline
\end{tabular}

transition matrix. Cure was defined as a transition to the M0 stage.

Wound Healing Progress. Treatment allocation of the lesions was masked during the assessment of wound healing progress. An expert in veterinary wound healing (JW) examined all photographs made during the treatment period for skin necrosis, granulation tissue, granulation tissue level in comparison with the surrounding skin, granulation tissue necrosis, wound contraction, and epithelization. Sequential pairs of photographs of the lesions [i.e., d 0-d 3 (WHO-3), d 3-d 7 (WH3-7), d 7-d 10 (WH7-10), and d 0-d 10 (WH0-10, primary outcome)] were given an evaluation of wound healing progress: improved, equal, worsened, or unable to score (Figure 2). Lesions with improved wound healing had at least 1 of the following criteria when compared with the previous observation: decreased defect size, healthier granulation tissue color (pink-red instead of purple-grayish), more regular aspect of granulation tissue surface, wound contraction, or epithelization starting from the surrounding skin. Wound healing progress that was unable to be scored was specified as presence of crust materials, presence of fecal contamination, poor image quality, or other. The end of the treatment period (d 10) was the endpoint of the wound healing assessment.

\section{Statistical Analysis}

Data were analyzed using the statistical software package $\mathrm{R}$ (R Core Team, 2014). The experimental unit was a lesion at stage M1, M2, or M4.1 on a hind foot at recruitment $(\mathrm{d} 0)$.

$M$-Score. The primary outcome for the M-score was analyzed in a logistic regression analysis of MS0-10 (improved or not improved, using the same definitions as for the M-score treatment outcome; Table 1). To enable assessment of the effect of different time periods under bandage (7 versus $10 \mathrm{~d}$ ), a variable "bandage" was cre-
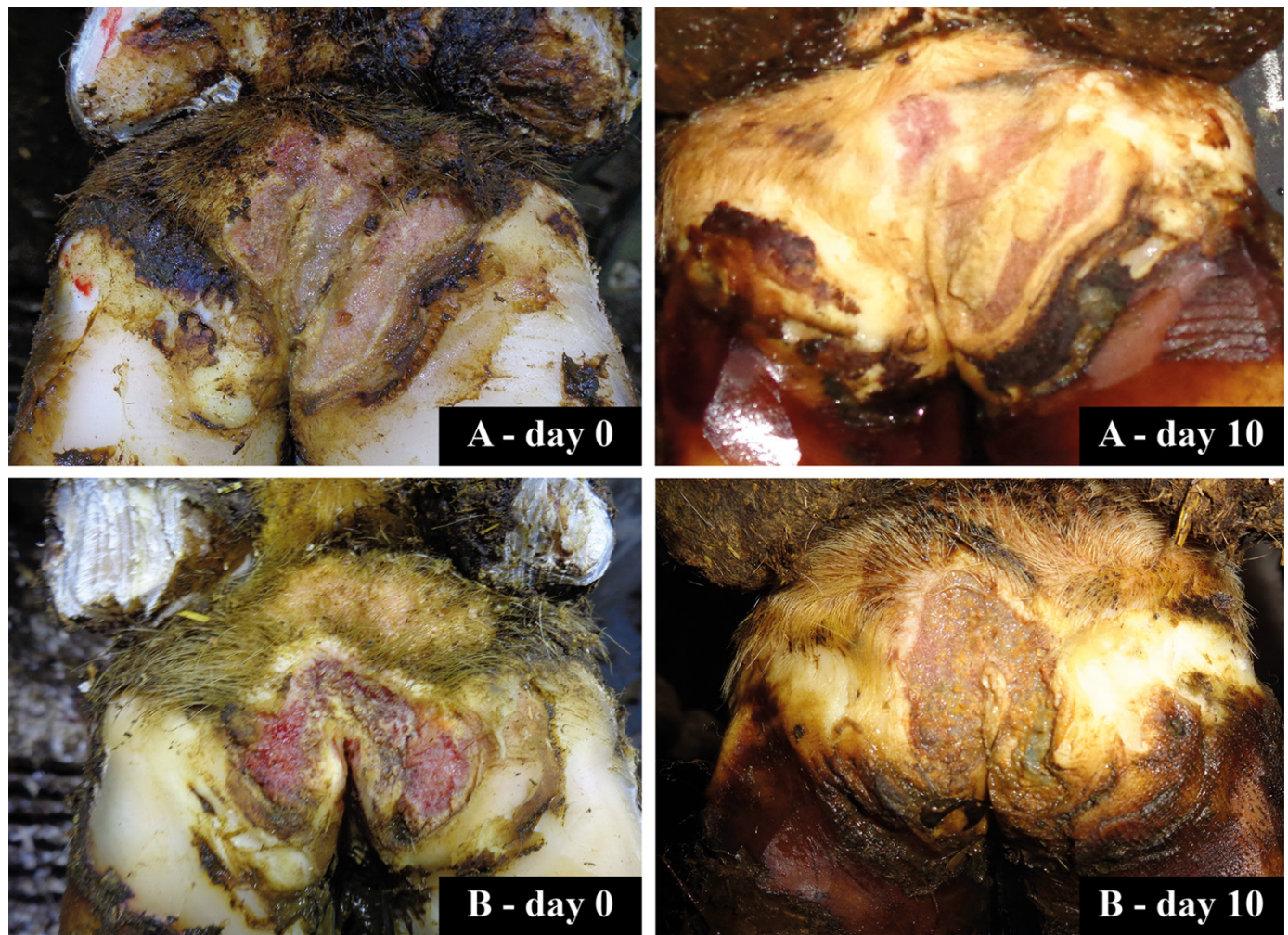

Figure 2. Digital photographs of a digital dermatitis lesion treated with enzyme alginogel, with (A) "improved" and (B) "not improved" wound healing progress during the 10 -d treatment trial. 


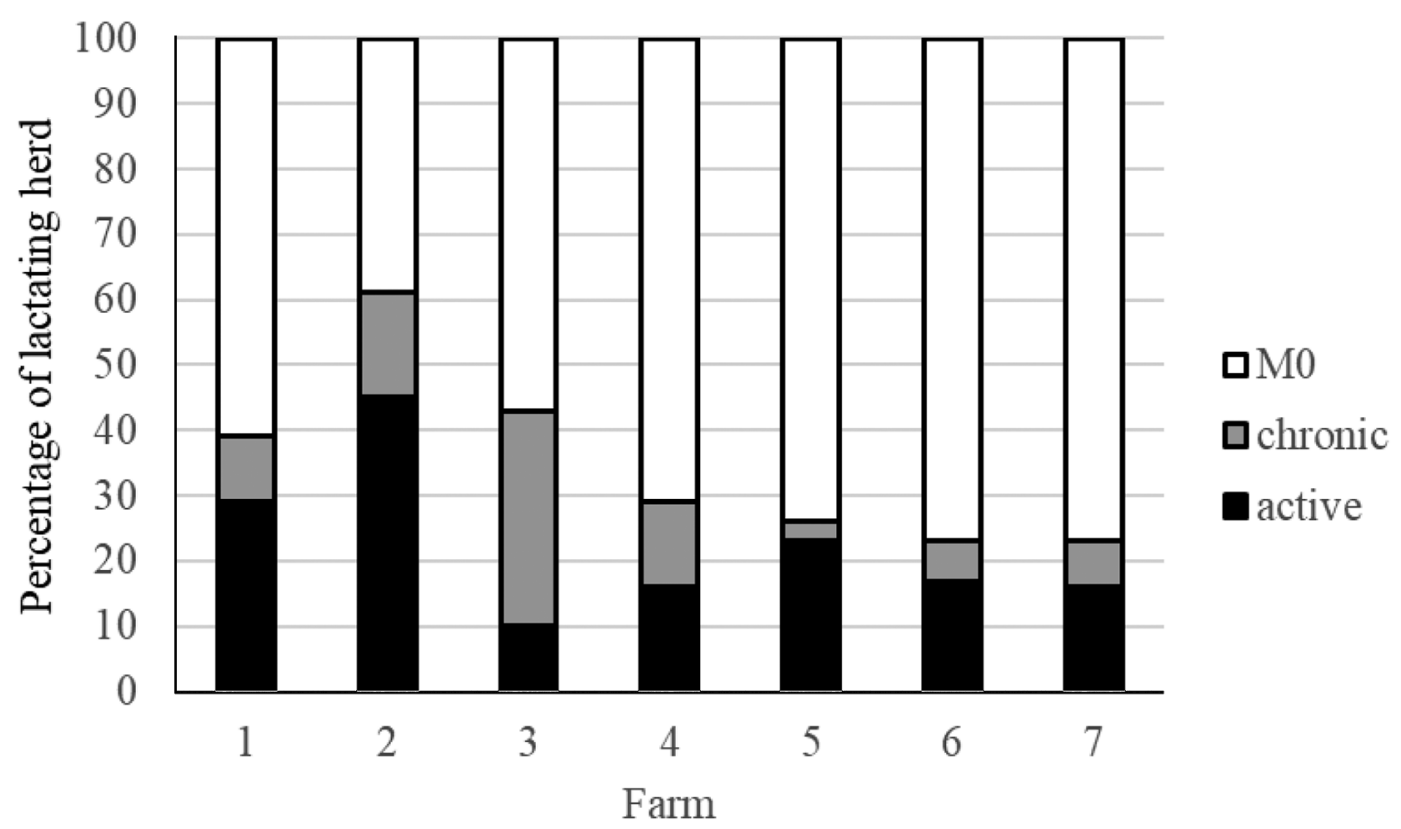

Figure 3. Feet-level prevalence of digital dermatitis in the lactating herd at recruitment for the study. Lesions of stages M1, M2, and M4.1 are grouped as active, and lesions at stages M3 and M4 are grouped as chronic (Döpfer et al., 1997; Berry et al., 2012; Zinicola et al., 2015). For herd 1, prevalence was determined from 43 out of 118 lactating cows, which were selected by the farmer for participation in the study.

ated. First, univariable logistic regression models were applied to assess the effect of treatment, M-score on d 0 , bandage, and farm, respectively, on MS0-10. This was followed by a multivariable model with treatment, M-score on d 0 , and bandage as independent variables, and farm as fixed effect. The final reduced model was based on the lowest Akaike information criterion using a backward elimination approach (Dohoo et al., 2014).

Wound Healing Progress. The primary outcome for wound healing progress was modeled in a logistic regression analysis of WH0-10 [improved or not improved (i.e., equal, worsened, and unable to score)]. First, univariable logistic regression models were applied to assess the effects of treatment, M-score on d 0, bandage, WH0-3, WH3-7, WH7-10, and farm, respectively, on WH0-10. This was followed by a multivariable model with treatment, M-score on d 0, bandage, WH0-3, WH3-7, and WH7-10 as independent variables, and farm as fixed effect, using the same backward elimination procedure as for the M-score.

\section{RESULTS}

\section{Lactating Herd DD Prevalence on Day 0 and Study Flow}

The lactating herd prevalence of active DD lesions at feet level on d 0 ranged between 10 and $45 \%$ (median: $17 \%$; first quartile: $16 \%$; third quartile: $26 \%$; Figure 3 ).
An overview of the study flow of hind feet recruited for the primary outcomes of this study is given in Figure 4. In total, 212 and 207 hind feet with active DD lesions were analyzed for MSO-10 and WH0-10, respectively.

\section{Treatment Outcomes}

M-Score at Day 10. The overall MS0-10 improvement (M-stage change from active to chronic or healed) was $27 \%$ for the alginogel group and $94 \%$ for the coppergel group, indicating inferiority of the alginogel at changing lesions from active to chronic or healed Mstages (Table 2). Of all treated lesions, $3 \%$ were cured (M-stage change from active to healed) by d 10, with $2 \%$ cured in the alginogel group and $4 \%$ cured in the coppergel group. In the alginogel group, M1-stage lesions mainly remained at M1 stage $(33 \%)$ or became M2, M3, or M4.1 lesions by d 10, whereas the majority of M2-stage lesions remained M2 lesions (77\%). In the coppergel group, however, active DD lesions were most likely to become M3-stage lesion $(75 \%)$ by d 10 . The full transition matrix for d $10 \mathrm{M}$-scores in relation to d 0 M-scores is given in the Appendix (Table A1).

Wound Healing Progress. Of the lesions treated with alginogel, $63 \%$ improved between d 0 and d 10, indicating inferiority of the coppergel with respect to wound healing progression (Table 3). Lesions with improved wound healing at d 10 compared with d 0 matched at least 1 of the following criteria: decreased 
Table 2. M-score improvement $10 \mathrm{~d}$ after treatment of active digital dermatitis lesions on hind feet from 171 cows on 7 dairy farms, with an enzyme alginogel or copper and zinc chelates gel (coppergel) with bandage ${ }^{1}$

\begin{tabular}{|c|c|c|c|c|}
\hline \multirow[b]{2}{*}{$\begin{array}{l}\text { M-score } \\
\text { on d } 0\end{array}$} & \multicolumn{2}{|r|}{ Alginogel } & \multicolumn{2}{|r|}{ Coppergel } \\
\hline & $\mathrm{N}$ & $\begin{array}{c}\text { M-score improvement, } \\
\text { N (\%) }\end{array}$ & $\mathrm{N}$ & $\begin{array}{c}\text { M-score improvement, } \\
\text { N (\%) }\end{array}$ \\
\hline M1 & 21 & $6(29)$ & 22 & $21(95)$ \\
\hline M2 & 72 & $17(24)$ & 77 & $71(92)$ \\
\hline M4.1 & 9 & $5(56)$ & 11 & $11(100)$ \\
\hline Total & 102 & $28(27)$ & 110 & $103(94)$ \\
\hline
\end{tabular}

${ }^{1} \mathrm{M}$-score improvement was defined as transition to M0, M3, or M4 stages or to lesions with a smaller ulcerative area (e.g., M2 stage to M1 stage).

${ }^{1}$ As developed by Döpfer et al. (1997) and extended by Berry et al. (2012).

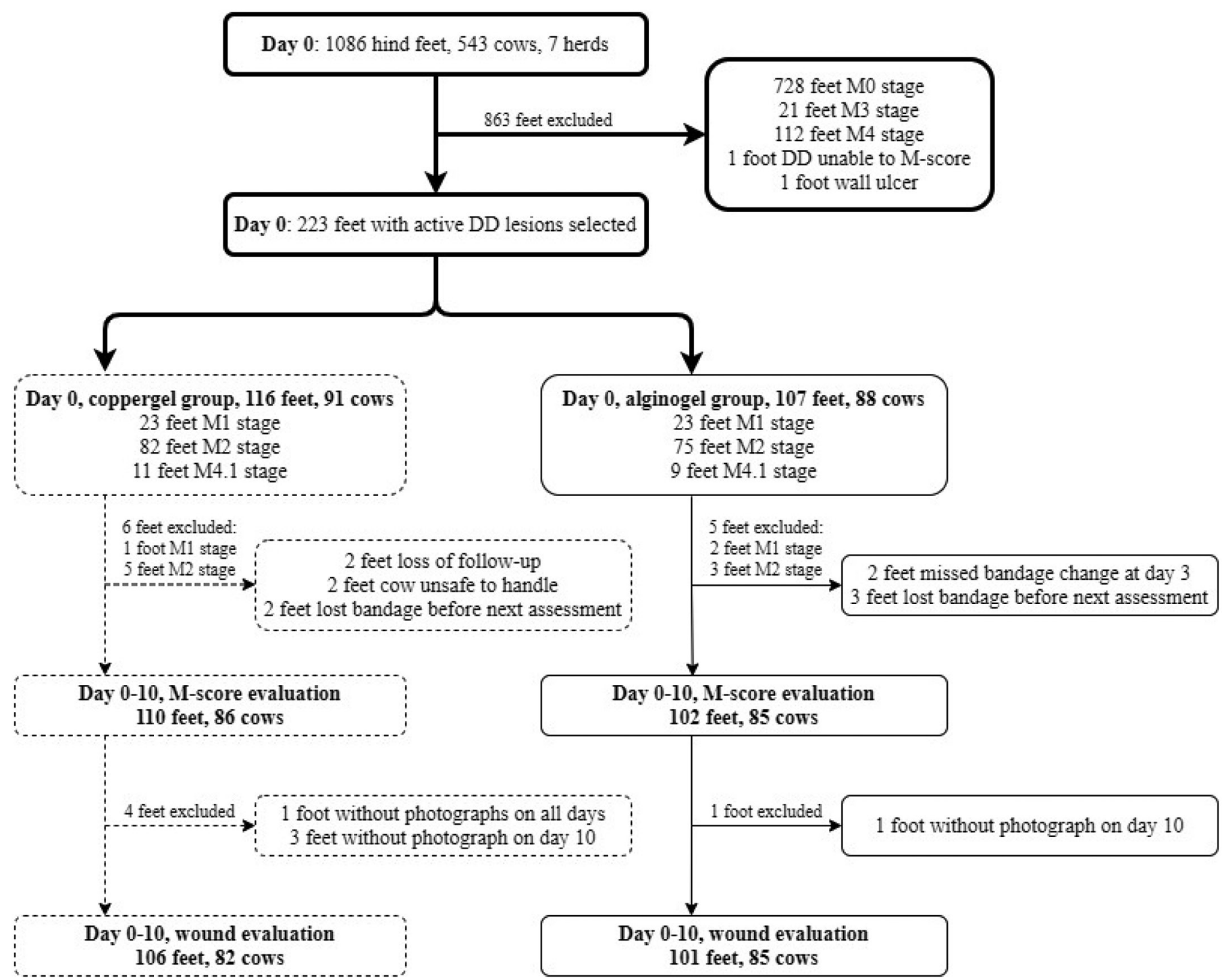

Figure 4. REFLECT study flowchart for an open-label, randomized clinical intention-to-treat, non-inferiority trial with positive control assessing the M-score improvement and wound healing progress of active digital dermatitis (DD) lesions (M1, M2, or M4.1 stage; Döpfer et al., 1997; Berry et al., 2012) on hind feet from lactating dairy cows on 7 dairy farms, treated with an enzyme alginogel or copper and zinc chelate gel (coppergel) with bandage. Bold solid lines represent general study recruitment; dotted lines represent the coppergel group; and light solid lines represent the alginogel group. 
Table 3. Overview of wound healing (WH) progress after treatment of active digital dermatitis lesions on hind feet from 167 cows on 7 dairy farms, with an enzyme alginogel or copper and zinc chelates gel (coppergel) with bandage ${ }^{1}$

\begin{tabular}{lcc}
\hline $\begin{array}{l}\text { Evaluation pair, wound } \\
\text { healing progress }\end{array}$ & $\begin{array}{c}\text { Alginogel } \\
\text { N }(\%)\end{array}$ & $\begin{array}{c}\text { Coppergel } \\
\text { N }(\%)\end{array}$ \\
\hline N hind feet & $101(100)^{2}$ & $106(100)$ \\
WH0-10 & & \\
Improved & $64(63)$ & $22(21)$ \\
Equal & $27(27)$ & $10(9)$ \\
Worsened & $2(2)$ & $2(2)$ \\
Unable to score & $8(8)$ & $72(68)$ \\
WH0-3 & $30(30)$ & $13(13)$ \\
Improved & $38(37)$ & $11(10)$ \\
Equal & $1(1)$ & 0 \\
Worsened & $32(32)$ & $82(78)$ \\
Unable to score & & \\
WH3-7 & $31(31)$ & $9(8)$ \\
Improved & $33(33)$ & $8(8)$ \\
Equal & $2(2)$ & $1(1)$ \\
Worsened & $34(34)$ & $88(83)$ \\
Unable to score & & \\
WH7-10 & & $7(7)$ \\
Improved & $23(23)$ & $8(8)$ \\
Equal & $7(7)$ & $3(3)$ \\
Worsened & $21(21)$ & $88(82)$ \\
Unable to score &
\end{tabular}

${ }^{1}$ Lesions with improved wound healing had at least 1 of the following criteria when compared with the previous observation: decreased defect size, healthier granulation tissue color (pink-red instead of purple-grayish), more regular aspect of granulation tissue surface, wound contraction, or epithelization starting from the surrounding skin. Percentages add up vertically per evaluation pair.

${ }^{2}$ For WH3-7 and WH7-10, the d-7 photograph was missing for 1 foot. ${ }^{3}$ Primary outcome, wound healing progress between $\mathrm{d} 0$ and $\mathrm{d} 10$.

${ }^{4}$ Wound healing progress between $\mathrm{d} 0$ and $\mathrm{d} 3$.

${ }^{5}$ Wound healing progress between $\mathrm{d} 3$ and $\mathrm{d} 7$.

${ }^{6}$ Wound healing progress between $\mathrm{d} 7$ and $\mathrm{d} 10$.

defect size, healthier granulation tissue color (pinkred instead of purple-grayish), more regular aspect of granulation tissue surface, wound contraction, or epithelization starting from the surrounding skin. The WH0-10 for the majority of the lesions treated with the coppergel could not be assessed (68\%), mostly due to the presence of crust materials (Table 4; Figure 5). Of the remaining lesions treated with the coppergel, $21 \%$ improved (Table 3). The M-scores on d 10 for those feet

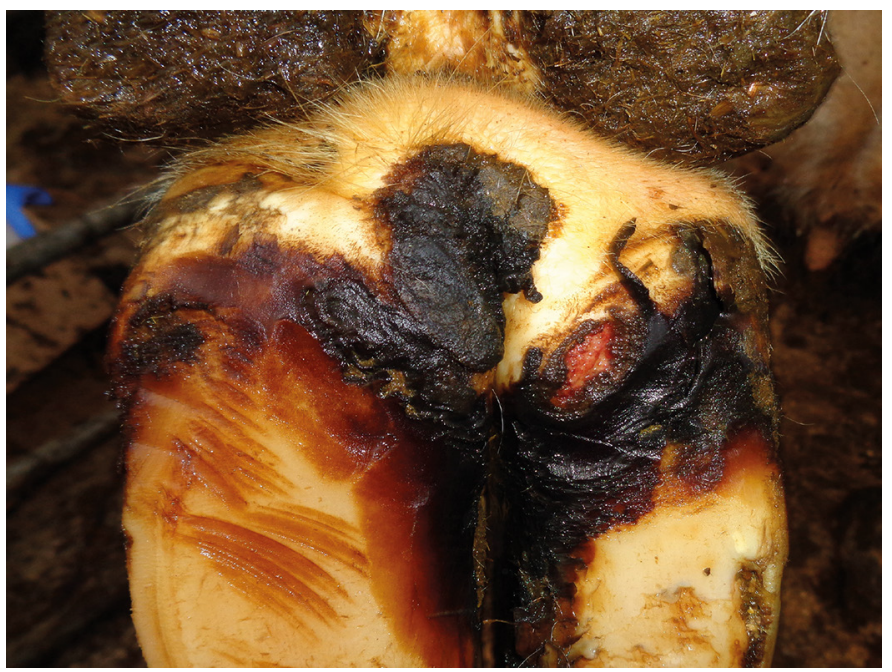

Figure 5. Digital color photograph of a digital dermatitis lesion covered with crusts, $10 \mathrm{~d}$ after treatment with copper and zinc chelate gel under bandage.

for which WH0-10 could not be scored are provided in the Appendix (Table A2).

\section{Logistic Regression Analyses}

$M$-Score. The results of the univariable logistic regression analyses are provided in the Appendix (Table A3). In the final multivariable model, lesions treated with alginogel had a 20 -fold decreased odds ratio for M-stage change from active to chronic or healed [improved MS0-10, adjusted odds ratio (aOR): 0.04; 95\% CI: 0.01-0.11; Table 5) compared with lesions treated with coppergel.

Wound Healing Progress. To deal with the large proportion of lesions for which WH0-10 could not be scored, these lesions were first classified as "improved" for the logistic regression analyses, followed by classification as "not improved" and repetition of the logistic regression analyses. The results of the univariable logistic regression analyses are provided in the Appendix (Table A3). With unscorable lesions classified as "im-

Table 4. Overview of reasons for inability to score wound healing progress between $\mathrm{d} 0$ and $\mathrm{d} 10$ of active digital dermatitis lesions on hind feet from 167 cows on 7 dairy farms, after treatment with an enzyme alginogel or copper and zinc chelates gel (coppergel) with bandage

\begin{tabular}{lccc}
\hline Item & $\begin{array}{c}\text { Alginogel } \\
(\mathrm{n}=101) \mathrm{N}(\%)\end{array}$ & $\begin{array}{c}\text { Coppergel } \\
(\mathrm{n}=106) \mathrm{N}(\%)\end{array}$ & $\begin{array}{c}\text { Total } \\
(\mathrm{n}=207) \mathrm{N}(\%)\end{array}$ \\
\hline $\mathrm{N}$ hind feet unable to score & $8(100)$ & $72(100)$ & $80(100)$ \\
Presence of crust materials & 0 & $51(71)$ & $51(64)$ \\
Presence of fecal contamination & $1(13)$ & $16(22)^{1}$ & $17(21)$ \\
Poor photograph quality & $6(74)$ & $4(6)$ & $10(13)$ \\
Other & $1(13)$ & $1(1)$ & $2(2)$ \\
\hline
\end{tabular}

${ }^{1}$ Of these 16 feet, 15 were not bandaged between $\mathrm{d} 7$ and $\mathrm{d} 10$. 
Table 5. Final reduced multivariable logistic regression analysis results for the associations between dichotomous outcome variables, M-score improvement and wound healing (WH) progress (with unscorable lesions classified as either "not improved" or "improved") between d 0 and d 10 , and different explanatory variables with farm as fixed effect (results not presented) ${ }^{1}$

\begin{tabular}{|c|c|c|c|c|c|c|}
\hline \multirow[b]{3}{*}{ Variable } & \multirow{2}{*}{\multicolumn{2}{|c|}{ M-score improvement ${ }^{2}$}} & \multicolumn{4}{|c|}{$\begin{array}{l}\text { Wound healing progress: } \\
\text { Unscorable lesions }\end{array}$} \\
\hline & & & \multicolumn{2}{|c|}{ Not improved } & \multicolumn{2}{|c|}{ Improved } \\
\hline & $\mathrm{aOR}^{3}$ & $95 \%$ CI & $\mathrm{aOR}$ & $95 \% \mathrm{CI}$ & $\mathrm{aOR}$ & $95 \% \mathrm{CI}$ \\
\hline Intercept & 0.80 & & 0.10 & & 0.14 & \\
\hline \multicolumn{7}{|l|}{ Treatment group } \\
\hline \multicolumn{7}{|l|}{ M-score ${ }^{4}$ on d 0} \\
\hline M2 & 3.09 & $0.79-15.76$ & & & & \\
\hline M4.1 & 16.79 & $2.33-150.61$ & & & & \\
\hline \multicolumn{7}{|c|}{ Period under bandage } \\
\hline $7 \mathrm{~d}$ & 17.92 & $4.69-98.87$ & & & & \\
\hline \multicolumn{7}{|l|}{ Not improved } \\
\hline \multicolumn{7}{|l|}{ WH7-10 } \\
\hline Not improved & & & & & & \\
\hline Improved & & & 27.07 & $8.71-107.90$ & 41.27 & $13.60-154.08$ \\
\hline
\end{tabular}

${ }^{1}$ Data were collected from active digital dermatitis lesions on hind feet from 171 cows on 7 dairy farms (M-score improvement) or 167 cows (due to loss of follow-up) on the same 7 dairy farms (wound healing progress), treated with an enzyme alginogel or copper and zinc chelates gel (coppergel) with bandage. M-score improvement was defined as transition to M0, M3, or M4 stages or to lesions with a smaller ulcerative area (e.g., M2 stage to M1 stage). Lesions with improved wound healing had at least 1 of the following criteria when compared with the previous observation: decreased defect size, healthier granulation tissue color (pink-red instead of purple-grayish), more regular aspect of granulation tissue surface, wound contraction, or epithelization starting from the surrounding skin.

${ }^{2}$ Variables WH0-3, WH3-7, and WH7-10 were not included in the M-score improvement logistic regression analysis.

${ }^{3}$ Adjusted odds ratio.

${ }^{4}$ As developed by Döpfer et al. (1997) and extended by Berry et al. (2012).

${ }^{5}$ Wound healing progress between $\mathrm{d} 0$ and $\mathrm{d} 3$.

${ }^{6}$ Wound healing progress between $\mathrm{d} 3$ and $\mathrm{d} 7$.

${ }^{7}$ Wound healing progress between d 7 and d 10 .

proved," we found no treatment effect on WH0-10 in the multivariable model (aOR: 0.99; 95\% CI: 0.34-3.05; Table 5). In contrast, with unscorable lesions classified as "not improved," the alginogel WH0-10 outperformed the coppergel (aOR: 2.48; 95\% CI: 1.07-5.79; Table 5).

\section{DISCUSSION}

This study investigated the effect of 2 nonantibiotic topical treatment products on active DD lesions using M-score improvement and wound healing progress as primary outcome measures. It is important to differentiate the M-score classification from wound healing progress classification. The M-score classification system was developed by Döpfer (Döpfer, 1994) from a cross-sectional observational study, with histopathological findings of the M-score classes added later (Döp- fer et al., 1997). Although the M-score classification system describes the epidemiological progress of DD in cows, the classification differs from current understanding of optimal wound healing progress in secondintention healing. Second-intention wound healing is a complex, dynamic process of 4 strongly interrelated phases (hemostasis, acute inflammatory phase, proliferative phase, and remodeling; Stadelmann et al., 1998; Shearer et al., 2015; Theoret, 2017).

At the end of the 10-d treatment trial, M-score improvement was high for lesions treated with coppergel, with most of the active lesions transitioned into chronic M3- or M4-stage lesions. By contrast, M-score improvement was low for lesions treated with alginogel, with most of the lesions remaining active M1-, M2-, or M4.1-stage lesions. The high M-score improvement of lesions treated with coppergel is in line with findings 
by others (Holzhauer et al., 2011; Dotinga et al., 2017). Copper has an astringent effect, which dries the lesion and stimulates crust formation, resulting in transition to M3-stage lesions, which is the characteristic reaction to topical treatment products (Döpfer et al., 1997). The alginogel, on the other hand, has a debriding and moisturizing effect (Strohal et al., 2013; Jacobsen, 2017; Jones and Oates, 2018), which apparently results in the majority of the lesions remaining active DD lesions during a treatment period of $10 \mathrm{~d}$. It is possible that the treatment period was not long enough for active lesions to transition to chronic or healed M-stages in the alginogel group. For udder clef dermatitis lesions with broken skin barrier, van Werven et al. (2018) reported that median time to first improvement with daily application of alginogel varied between 1 and 4 wk, depending on lesion size, and fewer than $10 \%$ of severe udder cleft dermatitis lesions were cured after a 12-wk treatment period.

In the final multivariable model, a shorter period under bandage had an increased likelihood for M-score improvement. The protocol for bandage duration was based on M-stage at the intermediate evaluation on $\mathrm{d} 7$, with discontinued treatment (and left without bandage) of M0-, M3-, and M4-stage lesions at d 7. This caused a high correlation between chronic lesions and bandage cessation at $\mathrm{d} 7$. In the coppergel group, $72 \%$ were chronic lesions by $\mathrm{d} 7$, whereas in the alginogel group this was only $11 \%$ (Appendix, Table A4). Of the M0-, M3-, and M4-stage lesions on d 7 (with discontinued treatment), only $6 \%$ had reverted to active DD lesions by d 10 (Appendix, Table A4). This low percentage of reversion of chronic or healed lesions to active DD lesions is a probable explanation for the positive association between short bandage duration and M-score improvement between d 0 and d 10. Compared with treatment protocols without bandage, other research supports a positive association between bandaging and M-score improvement of DD lesions (Higginson Cutler et al., 2013; Klawitter et al., 2019).

One limitation of our study is that, in both treatment groups, about $25 \%$ of cows received the same treatment on both hind feet. It is possible that the results of our study are biased by an unmeasured cow effect. When we randomly excluded 1 foot per cow, the estimates of the final multivariable models were very similar but with larger $95 \%$ CI, indicating more uncertainty for the estimates (Appendix, Table A5). Another limitation is the short duration of follow-up in our study. Most other studies incorporated a lesion assessment at d 28 after topical treatment, with lower M-score improvement rates than earlier assessments, due to recrudescence of lesions or development of new lesions (Berry et al., 2010; Holzhauer et al., 2011; Paudyal et al., 2020).
We detected more improved wound healing progress in the alginogel group than in the coppergel group. However, wound healing progress could not be evaluated for a large proportion of lesions in the coppergel group, due to the presence of crust materials. Crusts hamper the assessment of wounds, as removal of the crust might reveal a healthy, healing wound or an infected wound. The presence of crusts in general impedes wound healing, as it delays epithelization (Kunugiza et al., 2010). The conclusions about the wound healing properties of the 2 products changed considerably when wounds under crusts were assumed to be improved or not improved. As neither of these 2 extremes is likely to be the truth, we suggest that further research on healing of DD lesions that avoids the formation of crusts (M3 stage) is needed. Alongside dealing with the aspects of wound healing, new treatment products for DD lesions should also be assessed in light of reduction of lesion pain and accompanying lameness.

Digital dermatitis lesions could be considered infected wounds, as bacterial (Treponema spp.) contamination and colonization has surpassed the local defense mechanisms of the cow, resulting in interruption of the skin, unhealthy granulation-like tissue, and poor healing progression (Lipsky et al., 2016). In vitro work has identified that exposure of bovine macrophages to Treponema phagedenis-like spirochetes impairs their innate immune response and wound repair functions (Zuerner et al., 2007). Topical treatment with dressings with antimicrobial properties can help the immune system to overcome the infection, allowing second-intention wound healing. Copper has good antimicrobial properties but is likely too astringent and results in formation of crusts. The GLG-enzyme system in alginogel has the potential to resolve the infection, but possibly treatment duration in our study was too short to achieve completion of the wound healing process. For both copper and the GLG-enzyme system, efficacy against pathogenic Treponema spp. in DD still needs to be demonstrated, both in vitro and in vivo.

In general, topical treatment is applied to active lesions of DD, as these lesions are most painful (Higginson Cutler et al., 2013). With transition of active lesions to chronic lesions, following topical treatment, the painful aspect of DD is usually mitigated, and the disease is kept in a manageable state (Döpfer and Bonino Morlán, 2008). However, chronic M4-stage lesions have been identified as an important source of transmission of DD within herds (Biemans et al., 2018). We hypothesize that a topical treatment product and protocol with a swift return to the M0 stage as outcome, instead of the chronic DD stages, would not only improve the welfare of the treated cows but likely also help in herd-level DD control. 


\section{CONCLUSIONS}

We investigated the effect of 2 nonantibiotic topical treatment products on M-score improvement and wound healing progress of active DD lesions. Coppergel outperformed alginogel in M-score improvement, resulting in a manageable state of disease, with the majority of lesions remaining in the chronic state. In contrast, the alginogel achieved improved wound healing progress compared with the coppergel. However, none of the products used in our study achieved high cure rates (return to the M0 stage) for active DD lesions. Future research is needed to identify what is needed to achieve successful wound management of DD lesions and thereby mitigate pain associated with the lesions and reduce both transmission and prevalence of DD within herds.

\section{ACKNOWLEDGMENTS}

We thank the students Chantal Breedveld, Jessie Hesseling, Alger Hiemstra, and Simone Leeuwestein (Master in Veterinary Medicine, Faculty of Veterinary Medicine, Utrecht University, Utrecht, the Netherlands) for their help in collecting the data. We also thank the farmers, veterinarians, and hoof trimmers for their collaboration, effort, and enthusiasm; Dennis Kamphuis (Flen Health, Esch sur Alzette, Luxembourg) for his time and expertise related to wound healing and the enzyme alginogel; Steven Sietsma (ULP, Harmelen, the Netherlands) for his help coordinating data collection; Peter Zuithoff (Julius Center for Health Sciences and Primary Care, University Medical Center Utrecht, Utrecht, the Netherlands) for sample size calculation; Hans Vernooij (Faculty of Veterinary Medicine, Utrecht University, Utrecht, the Netherlands) for his advice and help with the statistical analysis; Karin Orsel (Faculty of Veterinary Medicine, University of Calgary, Calgary, Canada) for providing the digital photographs for classroom training on M-scores; Anneleen Vanhoudt (Hyperion Group, Antwerp, Belgium) for preparing the photographs for the manuscript; Emma Strous (Faculty of Veterinary Medicine, Utrecht University, Utrecht, the Netherlands) for bringing the flow chart website www.app.diagrams.net to our attention; and Inge van Geijlswijk (Faculty of Veterinary Medicine, Utrecht University, Utrecht, the Netherlands) for her pharmaceutical analysis of the components in the 2 products used in the trial. The enzyme alginogel was kindly donated by Flen Health (Esch sur Alzette, Luxembourg). The wound healing progress evaluation was funded through Stichting Animales (Huizen, the Netherlands, www.animales.nl). The authors have not stated any conflicts of interest.

\section{REFERENCES}

Berry, S. L., D. H. Read, T. R. Famula, A. Mongini, and D. Döpfer. 2012. Long-term observations on the dynamics of bovine digital dermatitis lesions on a California dairy after topical treatment with lincomycin $\mathrm{HCl}$. Vet. J. 193:654-658. https://doi.org/10 .1016/j.tvj1.2012.06.048.

Berry, S. L., D. H. Read, R. L. Walker, and T. R. Famula. 2010. Clinical, histologic, and bacteriologic findings in dairy cows with digital dermatitis (footwarts) one month after topical treatment with lincomycin hydrochloride or oxytetracycline hydrochloride. J. Am. Vet. Med. Assoc. 237:555-560. https://doi.org/10.2460/ javma.237.5.555.

Biemans, F., P. Bijma, N. M. Boots, and M. C. M. de Jong. 2018. Digital dermatitis in dairy cattle: The contribution of different disease classes to transmission. Epidemics 23:76-84. https://doi .org/10.1016/j.epidem.2017.12.007.

Bowers, S., and E. Franco. 2020. Chronic wounds: Evaluation and management. Am. Fam. Physician 101:159-166.

Bruijnis, M.R.N., B. Beerda, H. Hogeveen, and E.N. Stassen. 2012. Assessing the welfare impact of foot disorders in dairy cattle by a modeling approach. Animal 6:962-970. https://doi.org/10.1017/ S1751731111002606.

De Smet, K., D. Van Den Plas, D. Lens, and P. Sollie. 2009. Preclinical evaluation of a new antimicrobial enzyme for the control of wound bioburden. Wounds 21:65-73.

Dohoo, I., W. Martin, and H. Stryhn. 2014. Veterinary Epidemiologic Research. 3rd ed. VER Inc.

Dolecheck, K., and J. Bewley. 2018. Animal board invited review: Dairy cow lameness expenditures, losses and total cost. Animal 12:1462-1474. https://doi.org/10.1017/S1751731118000575.

Döpfer, D. 1994. Epidemiological investigations of digital dermatitis on two dairy farms. DVM dissertation. Klinik für Rinderkrankheiten, Tierärztlichen Hochschule Hannover, Hannover, Germany.

Döpfer, D., and J. Bonino Morlán. 2008. The paradox of modern animal husbandry and lameness. Vet. J. 175:153-154. https://doi .org/10.1016/j.tvj1.2007.02.013.

Döpfer, D., A. A. H. M. ter Huurne, J. L. Cornelisse, A. J. A. M. van Asten, A. Koopmans, F. A. Meijer, Y. H. Schukken, I. Szakáll, W. Klee, and R. B. Bosma. 1997. Histological and bacteriological evaluation of digital dermatitis in cattle, with special reference to spirochaetes and Campylobacter faecalis. Vet. Rec. 140:620-623. https://doi.org/10.1136/vr.140.24.620.

Dotinga, A., R. Jorritsma, and M. Nielen. 2017. A randomised non-inferiority trial on the effect of an antibiotic or non-antibiotic topical treatment protocol for digital dermatitis in dairy cattle. Veterinary Evidence 2. https://doi.org/10.18849/ve.v2i4.111.

Higginson Cutler, J. H., G. Cramer, J. J. Walter, S. T. Millman, and D. F. Kelton. 2013. Randomized clinical trial of tetracycline hydrochloride bandage and paste treatments for resolution of lesions and pain associated with digital dermatitis in dairy cattle. J. Dairy Sci. 96:7550-7557. https://doi.org/10.3168/jds.2012-6384.

Holzhauer, M., C. J. Bartels, M. van Barneveld, C. Vulders, and T. Lam. 2011. Curative effect of topical treatment of digital dermatitis with a gel containing activated copper and zinc chelate. Vet. Rec. 169:555. https://doi.org/10.1136/vr.d5513.

Jacobsen, S. 2017. Update on wound dressings: Indications and best use. Equine Wound Management, 3rd ed. C. L. Theoret and J. Schumacher, ed. John Wiley \& Sons Inc.

Jones, J., and D. Oates. 2018. TIME to assess wounds-A clinical evaluation of Flaminal. Wounds UK 14:63-69.

Klawitter, M., D. Döpfer, T. B. Braden, E. Amene, and K. E. Mueller. 2019. Randomised clinical trial showing the curative effect of bandaging on M2-stage lesions of digital dermatitis in dairy cows. Vet. Rec. Open 6. https://doi.org/10.1136/vetreco-2017-000264.

Kunugiza, Y., T. Tomita, H. Moritomo, and H. Yoshikawa. 2010. A hydrocellular foam dressing versus gauze: Effects on the healing of rat excisional wounds. J. Wound Care 19:10-14. https://doi.org/ 10.12968/jowc.2010.19.1.46093.

Lazarus, G. S., D. M. Cooper, D. R. Knighton, D. J. Margolis, R. E. Percoraro, G. Rodeheaver, and M. C. Robson. 1994. Definitions 
and guidelines for assessment of wounds and evaluation of healing. Wound Repair Regen. 2:165-170. https://doi.org/10.1046/j.1524 $-475 X .1994 .20305 . x$.

Leaper, D. J., G. Schultz, K. Carville, J. Fletcher, T. Swanson, and R. Drake. 2012. Extending the TIME concept: What have we learned in the past 10 years? Int. Wound J. 9:1-19. https://doi.org/10 .1111/j.1742-481X.2012.01097.x.

Lipsky, B. A., M. Dryden, F. Gottrup, D. Nathwani, R. A. Seaton, and J. Stryja. 2016. Antimicrobial stewardship in wound care: A position paper from the British Society for Antimicrobial Chemotherapy and European Wound Management Association. J. Antimicrob. Chemother. 71:3026-3035. https://doi.org/10.1093/jac/dkw287.

Paudyal, S., D. Manriquez, A. Velasquez, J. K. Shearer, P. J. Plummer, P. Melendez, R. J. Callan, U. S. Sorge, H. Bothe, J. Velez, and P. J. Pinedo. 2020. Efficacy of non-antibiotic treatment options for digital dermatitis on an organic dairy farm. Vet. J. 255:105417. https://doi.org/10.1016/j.tvjl.2019.105417.

Plummer, P. J., and A. Krull. 2017. Clinical perspectives of digital dermatitis in dairy and beef cattle. Vet. Clin. North Am. Food Anim. Pract. 33:165-181. https://doi.org/10.1016/j.cvfa.2017.02.002.

R Core Team. 2014. R: A language and environment for statistical computing. R Foundation for Statistical Computing. https://www .R-project.org/.

Relun, A., R. Guatteo, P. Roussel, and N. Bareille. 2011. A simple method to score digital dermatitis in dairy cows in the milking parlor. J. Dairy Sci. 94:5424-5434. https://doi.org/10.3168/jds .2010-4054.

Schultz, G. S., R. G. Sibbald, V. Falanga, E. A. Ayello, C. Dowsett, K. Harding, M. Romanelli, M. C. Stacey, L. Teot, and W. Vanscheidt. 2003. Wound bed preparation: A systematic approach to wound management. Wound Repair Regen. 11(Suppl. 1):S1-S28. https:// doi.org/10.1046/j.1524-475X.11.s2.1.x.

Shearer, J. K., P. Plummer, and J. Schleining. 2015. Perspectives on the treatment of claw lesions in cattle. Vet. Med. (Auckl.) 6:273. https://doi.org/10.2147/VMRR.S62071.

Solano, L., H. W. Barkema, C. Jacobs, and K. Orsel. 2017. Validation of the M-stage scoring system for digital dermatitis on dairy cows in the milking parlor. J. Dairy Sci. 100:1592-1603. https:// doi.org/10.3168/jds.2016-11365.

Stadelmann, W. K., A. G. Digenis, and G. R. Tobin. 1998. Physiology and healing dynamics of chronic cutaneous wounds. Am. J. Surg. 176:26S-38S. https://doi.org/10.1016/S0002-9610(98)00183-4.

Strohal, R., J. Dissemond, J. Jordan O'Brien, A. Piaggesi, R. Rimdeika, T. Young, and J. Apelqvist. 2013. EWMA Document: Debridement An updated overview and clarification of the principle role of debridement. J. Wound Care 22(Suppl. 1):S1-S49. https:// doi.org/10.12968/jowc.2013.22.Sup1.S1.

Theoret, C. 2017. Physiology of wound healing. Equine Wound Management. 3rd ed. C. Theoret and J. Schumacher, ed. John Wiley \& Sons Inc.

Toussaint Raven, E. 1989. Trimming. Cattle Footcare and Claw Trimming. E. Toussaint Raven, ed. Farming Press.

van Werven, T., J. Wilmink, S. Sietsma, J. van den Broek, and M. Nielen. 2018. A randomized clinical trial of topical treatments for mild and severe udder cleft dermatitis in Dutch dairy cows. J. Dairy Sci. 101:8259-8268. https://doi.org/10.3168/jds.2017-13778.

Zinicola, M., F. Lima, S. Lima, V. Machado, M. Gomez, D. Döpfer, C. Guard, and R. Bicalho. 2015. Altered microbiomes in bovine digital dermatitis lesions, and the gut as a pathogen reservoir. PLoS One 10:e0120504. https://doi.org/10.1371/journal.pone.0120504.

Zuerner, R. L., M. Heidari, M. K. Elliott, D. P. Alt, and J. D. Neill. 2007. Papillomatous digital dermatitis spirochetes suppress the bovine macrophage innate immune response. Vet. Microbiol. 125:256-264. https://doi.org/10.1016/j.vetmic.2007.06.001.

\section{ORCIDS}

A. Vanhoudt $\odot$ https://orcid.org/0000-0003-2122-3708

J. Hesseling (1) https://orcid.org/0000-0001-7085-8879

M. Nielen $\odot$ https://orcid.org/0000-0001-6909-877X

R. Jorritsma () https://orcid.org/0000-0001-6692-7544

T. van Werven $\odot$ https://orcid.org/0000-0003-2391-0253 


\section{APPENDIX}

Table A1. Trimming chute M-score transition matrix of active digital dermatitis lesions on hind feet from 171 cows on 7 dairy farms between d 0 and d 10 following treatment with an enzyme alginogel or a copper and zinc chelates gel (coppergel); for each treatment group, percentages add up horizontally per M-score on d 0

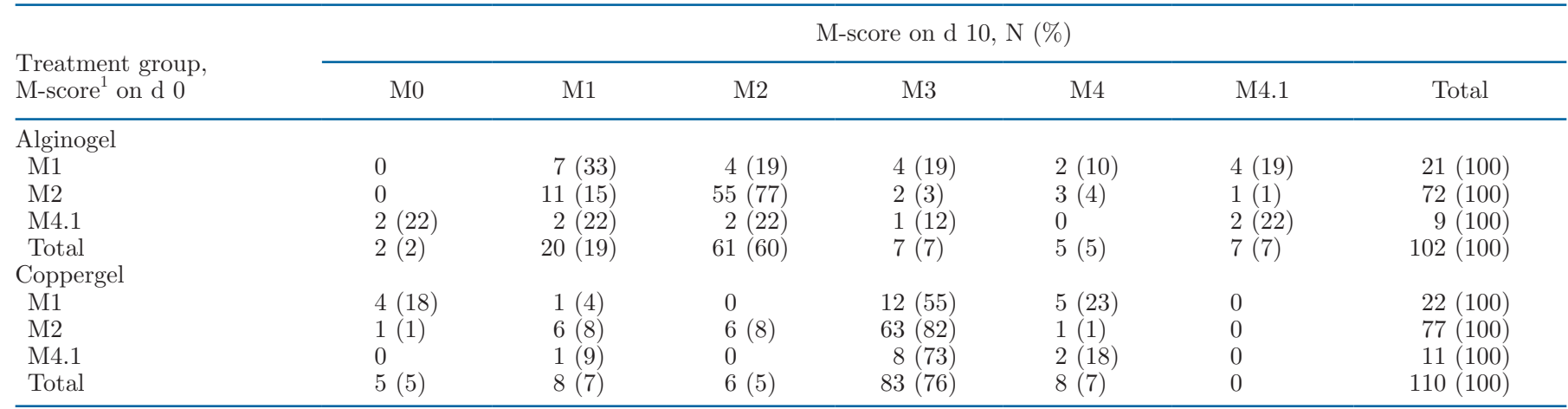

${ }^{1}$ As developed by Döpfer et al. (1997) and extended by Berry et al. (2012).

Table A2. Overview of the M-scores on d 10 per treatment group for feet with photographs classified as "unable to score" for wound healing progress of hind feet with M1, M2, or M4.1 digital dermatitis lesions on d 0 from 167 cows on 7 dairy farms, after treatment with an enzyme alginogel or copper and zinc chelates gel (coppergel) with bandage

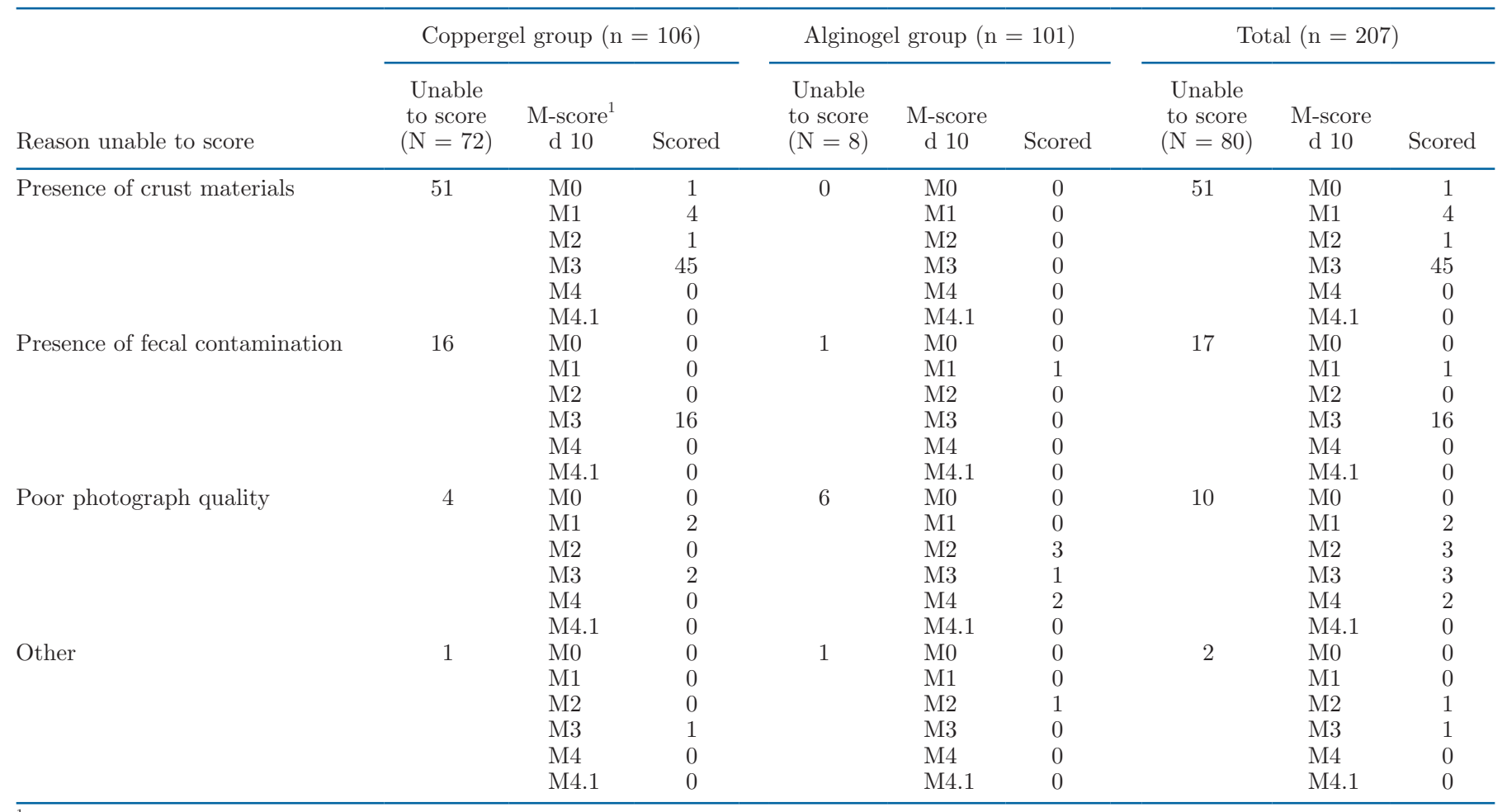

${ }^{1}$ As developed by Döpfer et al. (1997) and extended by Berry et al. (2012). 
Table A3. Associations between M-score improvement and wound healing (WH) progress between d 0 and d 10 outcome variables and different explanatory variables using univariable logistic regression analysis regardless of farm effect ${ }^{1}$

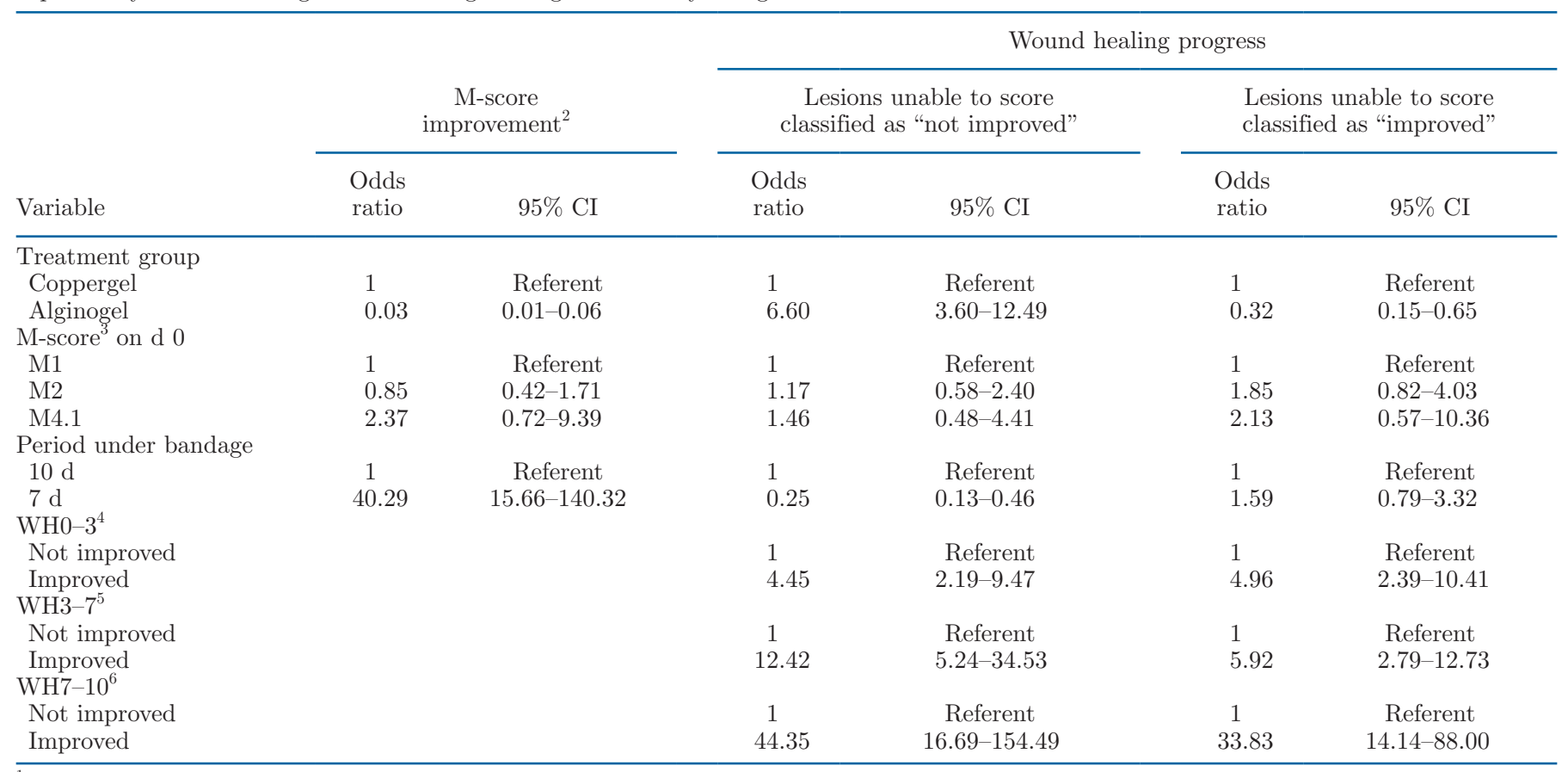

${ }^{1}$ Data were collected from active digital dermatitis lesions on hind feet from 171 cows on 7 dairy farms (M-score improvement) or 167 cows (due to loss of follow-up) on the same 7 dairy farms (wound healing progress), treated with an enzyme alginogel or copper and zinc chelates gel (coppergel) with bandage. M-score improvement was defined as transition to stages M0, M3, or M4, or to lesions with a smaller ulcerative area (e.g., stage M2 to M1). Lesions with improved wound healing had at least 1 of the following criteria when compared with the previous observation: decreased defect size, healthier granulation tissue color (pink-red instead of purple-grayish), more regular aspect of granulation tissue surface, wound contraction, or epithelization starting from the surrounding skin.

${ }^{2}$ Variables WH0-3, WH3-7, and WH7-10 were not included in the M-score improvement logistic regression analysis.

${ }^{3}$ As developed by Döpfer et al. (1997) and extended by Berry et al. (2012).

${ }^{4}$ Wound healing progress between $\mathrm{d} 0$ and $\mathrm{d} 3$.

${ }^{5}$ Wound healing progress between $\mathrm{d} 3$ and $\mathrm{d} 7$.

${ }^{6}$ Wound healing progress between $\mathrm{d} 7$ and $\mathrm{d} 10$. 
Table A4. Trimming chute M-score serial transition matrix of active digital dermatitis lesions on hind feet from 171 cows on 7 dairy farms between d 0, d 3, d 7, and d 10 following treatment with an enzyme alginogel (alginogel, $\mathrm{n}=102$ ) or a copper and zinc chelates gel (coppergel, $\mathrm{n}=110)$, for each treatment group

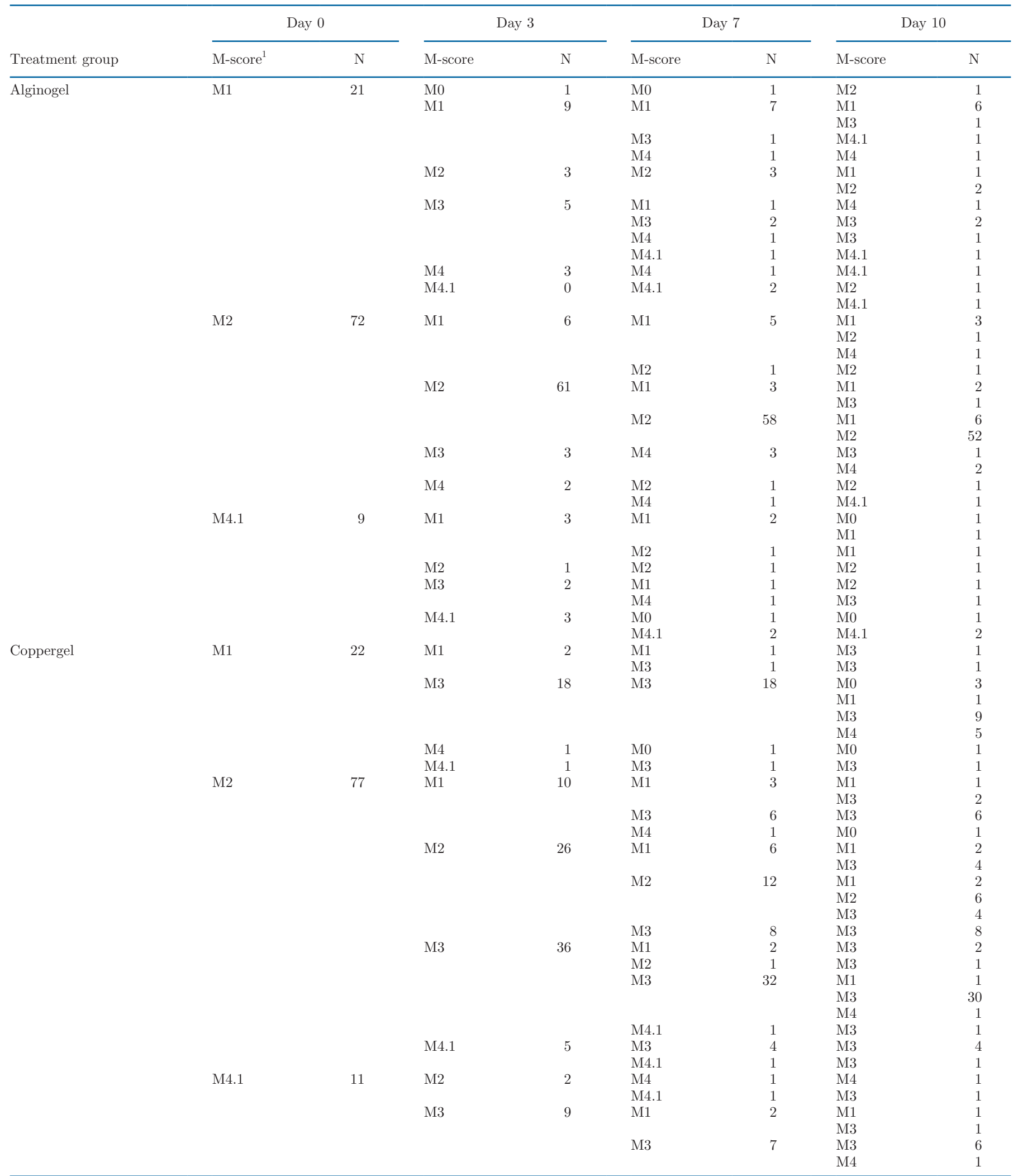

\footnotetext{
${ }^{1}$ As developed by Döpfer et al. (1997) and extended by Berry et al. (2012).
} 
Table A5. Final reduced multivariable logistic regression analysis results for associations between dichotomous outcome variables, M-score improvement and wound healing (WH) progress (with unscorable lesions classified as either "not improved" or "improved") between d 0 and d 10 , and different explanatory variables with farm as fixed effect (results not presented) with random selection of 1 digital dermatitis lesion per cow ${ }^{1}$

Wound healing progress:

Unscorable lesions

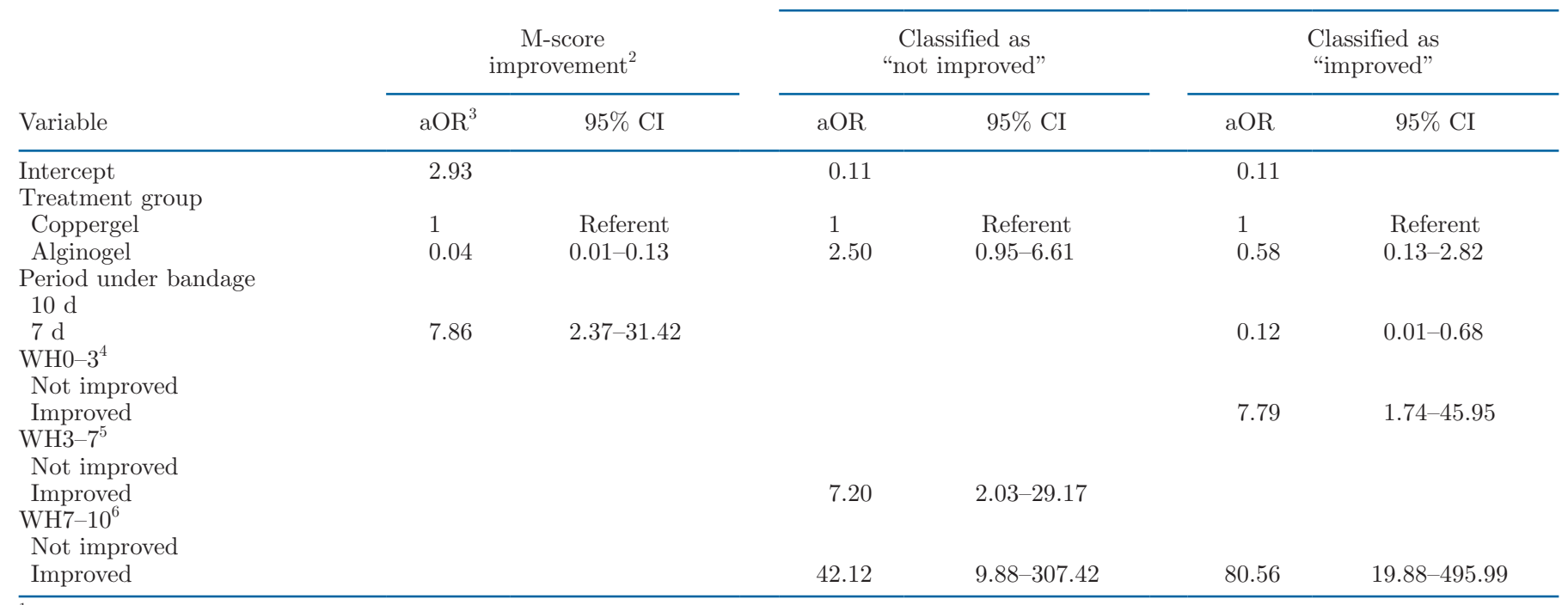

${ }^{1}$ Data were collected from active digital dermatitis lesions on hind feet from 171 cows on 7 dairy farms (M-score improvement) or 167 cows (due to loss of follow-up) on the same 7 dairy farms (wound healing progress), treated with an enzyme alginogel or copper and zinc chelates gel (coppergel) with bandage. M-score improvement was defined as transition to M0, M3, or M4 stages or to lesions with a smaller ulcerative area (e.g., stage M2 to M1). Lesions with improved wound healing had at least 1 of the following criteria when compared with the previous observation: decreased defect size, healthier granulation tissue color (pink-red instead of purple-grayish), more regular aspect of granulation tissue surface, wound contraction, or epithelization starting from the surrounding skin.

${ }^{2}$ Variables WH0-3, WH3-7, and WH7-10 were not included in the M-score improvement logistic regression analysis. M-scores are as developed by Döpfer et al. (1997) and extended by Berry et al. (2012).

${ }^{3}$ Adjusted odds ratio.

${ }^{4}$ Wound healing progress between $\mathrm{d} 0$ and $\mathrm{d} 3$.

${ }^{5}$ Wound healing progress between $\mathrm{d} 3$ and $\mathrm{d} 7$.

${ }^{6}$ Wound healing progress between $\mathrm{d} 7$ and $\mathrm{d} 10$. 